\title{
O desafio do estágio docente na Modalidade Remota como práxis em Mestrado Profissional em Psicologia da Saúde
}

\author{
The challenge of teaching internships in Remote Classes as a praxis on a \\ Professional Master's in Health Psychology
}

\author{
Luanna Lua Sousa Felício ${ }^{1}$ \\ Carmem Virgínia Moraes da Silva²
}

\section{Resumo}

No presente artigo, por meio de um relato de experiência, com a intenção de fornecer subsídios que fundamentem uma discussão no que concerne ao Estágio Docente no Ensino Superior, objetivamos explicitar o significado da realização de um estágio docente, realizado como componente curricular obrigatório em um Programa de PósGraduação, à nível de mestrado profissional, de Psicologia da Saúde, vinculado a uma Instituição de Ensino Superior (IES). A experiência descrita foi realizada na modalidade de ensino remoto no ano de 2021, em um cenário atípico, provocado pela Pandemia do Covid-19. Propomos a discussão da prática educativa, fundamentada na perspectiva freireana e apresentamos argumentos que compõem aspectos intrínsecos ao cenário mundial e à necessidade de adaptação da modalidade presencial para a remota, considerando, também, as nuances que envolvem a práxis educacional, como o planejamento, as funções exercidas, a escolha de plataformas, o encontro docentediscente, os atendimentos individualizados e coletivos, e os métodos avaliativos. Consideramos, então, que a pandemia provocou modificações na forma de ensinoaprendizagem, bem como no exercício da formação docente. No entanto, há aspectos fundamentais que sobressaíram às alterações como a vivência de lecionar no ensino superior, estando disponível e sensível ao processo dialógico de ensinar e aprender.

Palavras-chave: Ensino remoto. Mestrado profissional. Prática educativa. Práxis educacional. Psicologia da saúde.

\begin{abstract}
In this article, through a report on experience, we aim to present subsidies that substantiate a discussion regarding the Teaching Internship on High Education, with the

\footnotetext{
${ }^{1}$ Graduada em Psicologia (UFBA - IMS/CAT). Especialista em Terapia Cognitivo-Comportamental (UNIFG). Mestranda do Programa de Pós-Graduação em Psicologia da Saúde (UFBA - IMS/CAT). Membro integrante do Núcleo de Pesquisas e Estudos em Psicologia da UESB (NUPEP). E-mail: luannalua.psi@gmail.com

2 Pós-doutoranda em Psicologia (USP). Docente da Universidade Estadual do Sudoeste da Bahia (UESB) e do Programa de Pós-Graduação em Psicologia da Saúde (UFBA - IMS/CAT). Coordenadora do Núcleo de $\begin{array}{lllllll}\text { Pesquisas e } & \text { en } & \text { Psicologia } & \text { UESB } & \text { (NUPEP). }\end{array}$

E-mail: carmem.virginia@uesb.edu.br
} 


\section{-Revista de Iniciação à Docência, v.6, n.2, 2021- \\ Publicação: dezembro, 2021 - ISSN 2525-4332}

objective of showcasing the meaning of doing a teaching internship, done through a mandatory curricular component in a Post-Graduation Program, on the professional master's level, in Health Psychology, linked to a High Education Institution (HEI). The experience described was done through the remote teaching modality in the year of 2021, in an atypical scenario caused by the Covid-19 Pandemic. We propose a discussion on the education practice, based on the perspective of Freire and present arguments that compose intrinsically the worldwide scenario and the need to adapt from the on-site modality to remote, considering, as well, the nuances that involve the educational praxis, like planning, the functions exercised, the platform choices, the engagements between teachers and students, individualized and collective meetings, as well as the evaluative methods. Considering, then, that the pandemic caused changes in the way of teachinglearning, as well as in the exercise of the formation of a lecturer. Nonetheless, there are fundamental aspects that stand out from this alterations like the experience of teaching on High Education, being available and sensible to the dialogic process of teaching and learning.

Keywords: Remote teaching. Professional master's. Education practice. Educational práxis. Health psychology.

\section{Introdução}

No presente artigo, com intuito de promover uma discussão a respeito da realização e do significado de um Estágio Docente no Ensino Superior, apresentamos um relato do Estágio Docente, componente curricular obrigatório em programas de pósgraduação, na modalidade de mestrado acadêmico, bem como profissional. A atividade foi realizada no ano de 2021, em um momento atípico do cenário educacional, devido à Pandemia do Covid-19, conforme disposto na Resolução nº 10/2020 da UFBA, que instituiu que as atividades acadêmicas seriam desenvolvidas na modalidade não presencial, de modo a incluir, obrigatoriamente, atividades assíncronas e síncronas (respeitando dia e horário de oferta). Com a exposição deste relato, desejamos que seja possível explicitar, entre outras questões, o significado da realização de um estágio docente na modalidade do ensino remoto, à luz da perspectiva freireana, como atividade que aproxima o pósgraduando, de forma concreta, da atuação docente no ensino superior.

Em que pese a determinação de que os cursos de Psicologia devam obrigatoriamente oferecer, de forma adicional para o discente, a Formação de Professor de Psicologia (BRASIL, 2011), o objetivo dessa formação é:

complementar a formação dos psicólogos, articulando os saberes específicos da área com os conhecimentos didáticos e metodológicos, para atuar na construção de políticas públicas de educação, na educação básica, no nível médio, no curso Normal, em cursos profissionalizantes e em cursos técnicos, na educação continuada, assim como em contextos de educação informal como abrigos, centros socioeducativos, instituições comunitárias e outros. (BRASIL, 2011, p.5) 


\section{-Revista de Iniciação à Docência, v.6, n.2, 2021- \\ Publicação: dezembro, 2021 - ISSN 2525-4332}

Assim, mesmo que o aluno opte por cursar a Formação de Professor de Psicologia (pois é opcional para o aluno), o processo formativo não tem como foco o exercício no nível superior, permanecendo essa lacuna para aqueles que almejam ingressar na carreira docente.

O estágio docente orientado 3 aqui apresentado configura-se como parte da formação em uma pós-graduação. De acordo com a Instrução Normativa (IN) nº 01/2019 do programa em questão, no Art. $1^{\circ}$, Parágrafo Único:

A atividade obrigatória Estágio Docente Orientado tem como objetivo o
aperfeiçoamento da formação de estudantes de pós-graduação stricto sensu,
visando: o exercício da docência em ensino superior, por meio do estágio em
atividades de ensino de graduação no âmbito da Universidade e aprimorar a
formação de alunos de Pós-graduação "Stricto Sensu" desenvolvendo suas
capacidades didáticas, assim como a própria qualificação do ensino de
graduação. (UFBA, 2020, p.1)

Nesse sentido, compreendemos o Estágio Docente como uma ferramenta importante no contexto de formação profissional, vinculado ao mestrado, com o intuito de preparar os mestrandos quanto ao desenvolvimento de atividades acadêmicas, fazendo com que esses se desloquem do lugar/função de discente e passem a vivenciar um outro lado, ocupando o lugar/função de docente, o que é ratificado por Zanotto, Oliveira e Sommerhalder (2021, p.12), quando afirmam que o "desenvolvimento do ensino e o exercício da docência [...] demarcam posições de diálogo e preocupações no que se refere à formação inicial de professores".

Para a construção deste relato, nos amparamos na perspectiva freireana, especialmente no que diz respeito aos saberes necessários à prática educativa (FREIRE, 2011) considerando, então, que o docente/estagiário deva desenvolver o papel de facilitador e mediador do conhecimento e promover a relação dialógica no processo ensino-aprendizagem, de forma que possibilite uma prática docente crítica; que rompa com característica de passividade e/ou impositividade de ambos os lados; e que todos os atores envolvidos, dessa forma, constituam-se como agentes dinâmicos e protagonistas nesse processo.

Consideramos, portanto, que este relato faz-se relevante, uma vez que, ao realizar um breve levantamento em Bases de Dados, a exemplo da Scientific Electronic Library Online (SciELO) e da Periódicos Eletrônicos em Psicologia (PEPSIC), por meio de descritores como "formação", “estágio docente”, "psicologia”, “mestrado", encontramos poucos estudos que se vinculassem à experiência de alunos oriundos de um Programa de Pós-Graduação na realização do Estágio Docente.

Ademais, foi feita uma busca complementar no Scholar Google (Google Acadêmico), que apresentou uma quantidade maior de estudos, porém todos os achados

\footnotetext{
${ }^{3}$ O Estágio Docente é atividade obrigatória no Programa de Pós-Graduação em Psicologia da Saúde, a nível de Mestrado Profissional, vinculado à uma IES.
} 
referiam-se à relevância das supervisões em Psicologia, atividade voltada para a orientação de estagiários nos contextos clínico, social e organizacional, ou seja, vinculavase, em primazia, à função do supervisor ou tutor de estágio como docente de Psicologia.

Assim sendo, compreendemos a relevância deste relato através de um olhar lançado a partir da experiência docente de uma psicóloga e pós-graduanda a nível de mestrado profissional. Ressaltamos ainda, que, devido à especificidade desse tipo de mestrado, cujo objetivo é qualificar profissionais na atuação enquanto profissionais psicólogos, não há uma formação direcionada à preparação para a atuação docente, o que ocorreria de maneira diferente, se nos referíssemos ao mestrado acadêmico.

Para cumprir com o propósito exposto, estruturamos este artigo em quatro seções. Inicialmente, nesta Introdução, apresentamos o nosso objetivo e contextualizamos o nosso fazer; na sequência, trazemos a Metodologia, na qual explicitamos a modalidade de relato de experiência; em seguida, na seção Relato de Experiência, apresentamos as vivências em correlação com a fundamentação teórica; e, por fim, tecemos as nossas Considerações Finais, seguidas das Referências utilizadas no texto.

\section{Metodologia}

Para composição do texto em tela, utilizamos a metodologia de relato de experiência. Ressaltamos que a correlação e o olhar teórico sob a perspectiva freireana foram posteriores à realização do estágio, uma vez que a docente responsável pela condução da disciplina não utilizou explicitamente esse marco conceitual. Contudo, em sua prática, a docente responsável priorizou e utilizou de elementos dialógicos, problematizadores e de estímulo à autonomia dos alunos da disciplina, o que permitiu e convergiu com o olhar refletido neste relato. Assim sendo, a partir da descrição das atividades, apresentamos ponderações e reflexões dessa vivência profissional que, oriunda dos créditos obrigatórios de um Mestrado Profissional, configurou-se como uma prática significativa, possibilitando a experiência docente dentro do campo da Psicologia no ensino superior.

É válido mencionar que, na Instituição de Educação Superior (IES) na qual a estagiária docente cursou Psicologia, e mesma IES cuja experiência docente ocorreu, há um distanciamento entre a formação e as práticas docentes, por ser um Bacharelado e não apresentar possibilidade de formação com Licenciatura, até o momento atual. Desse modo, a experiência do estágio docente apresentou-se como a primeira experiência docente/educacional da mestranda voltada para a área em vigor.

Consideramos que o estágio docente foi uma vivência profissional exitosa quanto aos seus objetivos que, segundo a IN $\mathrm{n}^{\circ} 01$ de 2019 (UFBA, 2020), dizem respeito ao exercício da docência no ensino superior. Portanto, avaliamos a pertinência da 


\section{-Revista de Iniciação à Docência, v.6, n.2, 2021- \\ Publicação: dezembro, 2021 - ISSN 2525-4332}

apresentação deste relato, uma vez que pode (1) favorecer a partilha de conhecimentos; (2) contribuir para pesquisadores da área; (3) provocar reflexões aos pós-graduandos que se encontram nesta mesma fase do curso de Mestrado Acadêmico ou Profissional.

Neste texto, serão apresentadas informações sobre o estágio docente, as descrições das atividades desenvolvidas no componente curricular lócus do estágio, bem como as atividades desenvolvidas pela estagiária docente, no que tange os aspectos de planejamento, elaboração de materiais, ministração de aulas, participação em processos avaliativos, supervisão e orientação relativa a seminários e os atendimentos individuais e coletivos aos graduandos em Psicologia da IES que, no primeiro semestre de 2021, estavam matriculados no componente curricular "Psicoterapia Breve" (PB).

\section{Relato de experiência}

Nesta seção, destinada ao relato de experiência quanto ao estágio docente, temos como foco abordar: informações gerais sobre o estágio; planejamento, divisão de funções e escolha das plataformas; encontro docente-discente; atendimentos individuais e coletivos; e participação na avaliação.

\section{Informações gerais}

No relato desta experiência, alguns pontos iniciais são necessários para nos aproximarmos do processo realizado. De acordo com o Programa de Pós-Graduação em Psicologia da Saúde, o crédito referente ao "Estágio Docente Orientado", configurado como atividade obrigatória, deveria ser cumprido entre o segundo e o terceiro semestre letivo do Mestrado, de modo que a mestranda em questão o realizou em seu terceiro semestre de curso; e a escolha do componente deveria estar condicionada a ser um componente curricular em cursos de graduação e/ou pós-graduação lato sensu, cujo conteúdo estivesse vinculado à área da Psicologia da Saúde e às linhas de pesquisa dispostas no Mestrado em voga, quais sejam: Linha de Pesquisa 1 - Práticas Clínicas e Saúde Mental, que abarca estudos referentes ao processo saúde-doença, práticas de cuidado em saúde mental, abrangendo pesquisas e/ou intervenções realizadas no Sistema Único da Saúde (SUS) e na Clínica Ampliada; e a Linha 2 - Desenvolvimento Humano e Práticas Educativas na Saúde, com fins no estudo da saúde dos indivíduos nas diferentes fases do desenvolvimento humano, englobando pesquisas e/ou intervenções nos campos de avaliação psicológica, neuropsicologia do desenvolvimento, promoção da saúde e práticas educativas; por esta razão, e por afinidade, houve a escolha pelo componente curricular Psicoterapia Breve.

A experiência docente, realizada no componente curricular Psicoterapia Breve, teve a carga-horária de $68 \mathrm{~h}$, distribuídas em $34 \mathrm{~h}$ teóricas e $34 \mathrm{~h}$ práticas. $\mathrm{O}$ componente curricular referia-se a uma disciplina optativa, ministrada para uma turma composta por vinte e um (21) alunos, que se diversificavam em relação ao semestre, do $3^{\circ}$ ao $9^{\circ}$ no curso 


\section{-Revista de Iniciação à Docência, v.6, n.2, 2021- \\ Publicação: dezembro, 2021 - ISSN 2525-4332}

de Graduação em Psicologia com Habilitação em Formação de Psicólogo, ofertado por uma IES, durante um semestre, referente ao período letivo 2021.1, tendo início em 22 de fevereiro de 2021 e finalizando em 12 de junho de 2021, na modalidade remota/on-line devido à Pandemia do Covid-19.

Ainda no que concerne à Pandemia do Covid-19, podemos afirmar que muitos desafios nas nuances sociais, econômicas, pessoais, afetivas, políticas e sanitárias acarretaram todo o mundo. Especificamente, no que tange à situação brasileira, foi tido como requisito de proteção o isolamento social, com mínimo contato físico para evitar a contaminação e disseminação do vírus. Portanto, nesse novo cenário, mediante a necessidade advinda de uma questão de saúde pública, uma implicação importante diz respeito ao processo ensino-aprendizagem que sofreu alterações na forma de ocorrência, de maneira que foi necessário transpor o que acontecia de modo presencial para a forma remota, através das telas e com o uso de ferramentas e recursos tecnológicos como mediadores e facilitadores desse processo, o que, por sua vez, reverberou na necessidade de adaptação tanto da parte docente quanto discente.

Reforçamos, assim, que a mestranda não teve contato com a docência de modo presencial e a relação estabelecida foi unicamente remota, que fez com que a estagiária docente precisasse adquirir habilidades para o ensino remoto, de modo que, para além do conhecimento teórico/prático referente ao componente curricular, houve a necessidade de aprender e usar conceitos como síncrono/assíncrono, entender o funcionamento e saber como orientar alunos quanto ao uso das plataformas digitais, o que implica nos caminhos que foram utilizados para o ensino-aprendizagem. Considerando, ainda, fatores intrínsecos ao digital como a oscilação na internet ou dificuldade de acesso à transmissão em tempo real, conforme explanado por Inácio et al (2020).

No que tange aos desafios e dificuldades, Zanotto, Oliveira e Sommerhalder (2021), ao longo do seu texto, problematizam sobre como é possível atribuir qualidade ao ensino remoto "em tempos inéditos regidos por recomendações de isolamento social, interrupção de atividades presenciais, políticas de desvalorização da ciência e, muitas vezes, ausência de recursos tecnológicos, estruturais e humanos suficientes" (ZANOTTO, OLIVEIRA E SOMMERHALDER, 2021, p.2). Esse questionamento reflete o contexto de inseguranças e incertezas que permeiam o cenário pandêmico em paralelo com a formação de professores.

Essa é uma discussão emergente diante do cenário imposto pela pandemia, mas, conforme Arroyo (2000, citado por Silva, Rangel, Souza, 2020), o conhecimento se faz e refaz através das vivências e isso é parte fundamental do reconhecimento da dimensão humana. Desse modo, partimos do pressuposto que o ensino remoto, como prática emergencial, só pode ser discutido e avaliado em seus benefícios/malefícios a partir do momento que consideramos a pandemia enquanto fenômeno social, histórico e cultural 
e que provoca modificações em vários aspectos, dentre os quais, se destaca a educação, sendo essa a principal motivação e consequente desejo ao apresentar o presente relato, pois, como assevera Freire (2011, p.67), "a educação é uma forma de intervenção no mundo", de modo que essa se faz e é refeita constantemente na práxis, no decorrer do ser e do agir, como um processo que dá indícios de mudanças e transformações constantes à medida que as vivências vão ocorrendo (FREIRE, 1997).

\section{Planejamento, divisão de funções e escolha das plataformas}

Anteriormente ao início do componente curricular, foi realizada uma reunião entre a docente responsável pelo componente curricular e a mestranda para planejamento do componente como um todo. Nesse momento inicial, houve discussão envolvendo aspectos gerais da condução do componente, sugestões para as atividades avaliativas e, em conjunto, foi organizado o cronograma do componente com a proposta de temáticas por aula e divisão de tempo, considerando os momentos síncronos e assíncronos, de acordo com o Plano de Curso, cuja ementa está ilustrada a seguir.

Figura 1: Ementa do componente curricular

\begin{tabular}{|c|c|c|}
\hline \multicolumn{3}{|c|}{ DADOS DE IDENTIFICAÇAOO E ATRIBUTOS } \\
\hline CÓDIGO & NOME & COLEGLADO \\
\hline IMSD19 & PSICOTERAPIA BREVE & Curso de Psicologia \\
\hline \multicolumn{2}{|c|}{ MODALIDADE/SUBMODALIDADE } & Disciplina Optativa \\
\hline \multicolumn{2}{|c|}{ CARGA HORÁRIA } & NO DE VIGENCIA \\
\hline \multicolumn{2}{|c|}{$68 \mathrm{~h}-34 \mathrm{~h} \mathrm{P} / 34 \mathrm{~h}-\mathrm{T}$} & 2021.1 \\
\hline \multicolumn{3}{|c|}{ EMENTA } \\
\hline \multicolumn{3}{|c|}{$\begin{array}{l}\text { As psicoterapias breves no contexto psicoterápico. Teorias psicoterápicas e a } \\
\text { fundamentaçào da psicoterapia breve. Foco e situação problema. Critérios de seleçấo } \\
\text { para psicoterapia breve. Entrevistas preliminares. Planejamento tesapéutico: fases. } \\
\text { Recursos e problemas técnicos nas psicoterapias breves. Principais usos e limitaçỏes. } \\
\text { Questôes éticas. }\end{array}$} \\
\hline
\end{tabular}

Fonte: Imagem coletada pelas autoras.

Como pode ser visto na ementa, o componente curricular atendia o requisito estabelecido pelo mestrado, pois o conteúdo apresentava relação direta com a área da Psicologia da Saúde e com, pelo menos, uma das linhas de pesquisa, por abordar o processo saúde-doença e a prática de PB como uma prática de cuidado em saúde mental. Ainda no Plano de Curso, constavam os objetivos (geral e específicos), que, em suma, tangiam o conhecimento dos fundamentos teóricos, técnicos, práticos e éticos da PB, bem como as suas modalidades, critérios de aplicabilidade, recursos e limitações, 
-Revista de Iniciação à Docência, v.6, n.2, 2021-

Publicação: dezembro, 2021 - ISSN 2525-4332

aplicando essa compreensão na realização de atividades práticas de planejamento terapêutico e elaboração de protocolos de intervenção. Com o intuito de cumprir os objetivos, foi elaborado e enviado aos alunos um quadro com o cronograma (Quadro 1).

Quadro 1: Cronograma do componente curricular

\begin{tabular}{|c|c|c|}
\hline DATA & TEMA & PROPOSTA \\
\hline $02 / 03 / 2021$ & Apresentação da disciplina & $\begin{array}{l}\text { Aula síncrona } \\
7 \mathrm{~h} \text { às } 10 \mathrm{~h} 40 \mathrm{~m}\end{array}$ \\
\hline $09 / 03 / 2021$ & $\begin{array}{l}\text { PB: histórico, tipos, conceito e critérios } \\
\text { de indicação. }\end{array}$ & $\begin{array}{c}\text { Aula assincrona (leitura) } \\
7 \mathrm{~h} \text { às } 8 \mathrm{~h} \\
\text { Aula sincrona } \\
8 \mathrm{~h} \text { às } 10 \mathrm{~h} 40 \mathrm{~m}\end{array}$ \\
\hline $16 / 03 / 2021$ & $\begin{array}{c}\text { Aliança Terapêutica e Papel/Funçōes do } \\
\text { Terapeuta na PB }\end{array}$ & $\begin{array}{l}\text { Aula assincrona (leitura) } \\
\text { 7h ảs } 8 \mathrm{~h} \\
\text { Aula sincrona } \\
8 \mathrm{~h} \text { às } 10 \mathrm{~h} 40 \mathrm{~m}\end{array}$ \\
\hline $23 / 03 / 2021$ & $\begin{array}{l}\text { Aspectos técnicos: entrevista inicial e } \\
\text { contrato terapêutico na PB }\end{array}$ & $\begin{array}{c}\text { Aula assincrona (leitura) } \\
7 \mathrm{~h} \text { às } 8 \mathrm{~h} \\
\text { Aula sincrona } \\
8 \mathrm{~h} \text { às } 10 \mathrm{~h} 40 \mathrm{~m}\end{array}$ \\
\hline $30 / 03 / 2021$ & $\begin{array}{l}\text { Aspectos técnicos: foco, objetivos e } \\
\text { estratégias na PB }\end{array}$ & $\begin{array}{c}\text { Aula assincrona (leitura) } \\
7 \mathrm{~h} \text { às } 8 \mathrm{~h} \\
\text { Aula sincrona } \\
8 \mathrm{~h} \text { às } 10 \mathrm{~h} 40 \mathrm{~m}\end{array}$ \\
\hline $06 / 04 / 2021$ & $\begin{array}{l}\text { Aspectos técnicos: planejamento } \\
\text { terapêutico e aplicações }\end{array}$ & $\begin{array}{c}\text { Aula assincrona (leitura) } \\
\text { 7h às } 8 \mathrm{~h} \\
\text { Aula sincrona } \\
8 \mathrm{~h} \text { às } 10 \mathrm{~h} 40 \mathrm{~m}\end{array}$ \\
\hline $13 / 04 / 2021$ & $\begin{array}{c}\text { Aspectos técnicos: término da terapia } \\
\text { (manejo e critérios) e prevenção de } \\
\text { recaida }\end{array}$ & $\begin{array}{c}\text { Aula assincrona (leitura) } \\
7 \mathrm{~h} \text { às } 8 \mathrm{~h} \\
\text { Aula sincrona } \\
8 \mathrm{~h} \text { às } 10 \mathrm{~h} 40 \mathrm{~m}\end{array}$ \\
\hline $20 / 04 / 2021$ & $\begin{array}{c}\text { Criação do glossário com principais } \\
\text { termos utilizados na } \mathrm{PB} \text { com entrega } \\
\text { para } 27 / 04 / \mathbf{2 0 2 1}\end{array}$ & $\begin{array}{c}\text { Aula assíncrona } \\
\text { 7h às } 10 \mathrm{~h} 40 \mathrm{~m} \\
\text { (Tempo destinado para execução da } \\
\text { atividade) }\end{array}$ \\
\hline $27 / 04 / 2021$ & $\begin{array}{l}\text { Entrega do glossário via classroom. } \\
\text { Planejamento da apresentação e } \\
\text { Orientação sobre o seminário PB e } \\
\text { contextos de atuação }\end{array}$ & $\begin{array}{c}\text { Aula assincrona } \\
\text { 7h às } 10 \mathrm{~h} 40 \mathrm{~m} \\
\text { (Tempo destinado para reunião dos } \\
\text { grupos, planejamento da apresentação } \\
\text { da PB e contextos de atuação. Em } \\
\text { paralelo, ocorrerão as orientações com } \\
\text { horários agendados por grupo) }\end{array}$ \\
\hline $04 / 05 / 2021$ & $\begin{array}{c}\text { Aula da mestranda Luanna Lua - } \\
\text { Psicoterapia Breve no contexto da } \\
\text { saúde e hospitalar }\end{array}$ & $\begin{array}{c}\text { Aula assincrona (leitura) } \\
7 \mathrm{~h} \text { às } 8 \mathrm{~h} \\
\text { Aula sincrona } \\
8 \mathrm{~h} \text { às } 10 \mathrm{~h} 40 \mathrm{~m}\end{array}$ \\
\hline $11 / 05 / 2021$ & $\begin{array}{c}\text { Apresentação de seminário - } \\
\text { Psicoterapia Breve e contextos de } \\
\text { atuação. }\end{array}$ & $\begin{array}{l}\text { Aula sincrona } \\
7 \mathrm{~h} \text { as } 10 \mathrm{~h} 40 \mathrm{~m}\end{array}$ \\
\hline $18 / 05 / 2021$ & $\begin{array}{c}\text { Orientação: construção de plano de } \\
\text { intervenção com entrega para } \\
01 / 06 / 2021\end{array}$ & $\begin{array}{c}\text { Aula síncrona } \\
7 \mathrm{~h} \text { às } 10 \mathrm{~h} 40 \mathrm{~m} \\
\text { (Horários agendados por grupo) }\end{array}$ \\
\hline $25 / 05 / 2021$ & $\begin{array}{l}\text { Planejamento e elaboração da atividade } \\
\text { Plano de Intervenção em PB. }\end{array}$ & $\begin{array}{c}\text { Aula assíncrona } \\
7 \mathrm{~h} \text { às } 10 \mathrm{~h} 40 \mathrm{~m} \\
\text { (Tempo destinado para reunião dos } \\
\text { grupos e planejamento da atividade de } \\
\text { plano de intervenção em } \mathrm{PB} \text { ) }\end{array}$ \\
\hline $01 / 06 / 2021$ & $\begin{array}{l}\text { Entrega do plano de intervenção } \\
\text { (modalidade escrita) via classroom. } \\
\text { Apresentação oral do plano de } \\
\text { intervençāo. }\end{array}$ & $\begin{array}{l}\text { Aula sincrona } \\
7 \mathrm{~h} \text { às } 10 \mathrm{~h} 40 \mathrm{~m}\end{array}$ \\
\hline $08 / 06 / 2021$ & $\begin{array}{l}\text { Entrega de notas e encerramento da } \\
\text { disciplina. }\end{array}$ & $\begin{array}{l}\text { Aula sincrona } \\
7 \mathrm{~h} \text { às } 10 \mathrm{~h} 40 \mathrm{~m}\end{array}$ \\
\hline
\end{tabular}

Fonte: Imagem coletada pelas autoras.

Concernente ao previsto no componente curricular, em reunião com a docente responsável, foi realizada a distribuição das funções que deveriam ser desempenhadas ao 


\section{-Revista de Iniciação à Docência, v.6, n.2, 2021- \\ Publicação: dezembro, 2021 - ISSN 2525-4332}

longo do semestre, como: (1) o repasse de informações aos alunos, que consistia nos informes sobre o planejamento diário da aula e lembrete quanto aos prazos de entrega; (2) o envio de material de referência para leitura, de modo que a cada aula eram encaminhados materiais como livros e artigos em PDF para que os alunos pudessem ter compreensão prévia do conteúdo a ser discutido na aula seguinte e, dessa maneira, propiciar as discussões e reflexões sobre cada temática, com o intuito de instigar curiosidade e inquietação; (3) acompanhamento e recebimento das atividades avaliativas, no que se referia ao cumprimento de prazos estipulados para entrega de avaliações individuais e coletivas via Plataforma Google Classroom ${ }^{4}$, bem como (4) a solução de dúvidas que surgissem, que ficaram sob a responsabilidade da mestranda, isto é, à medida que os discentes não compreendessem alguma temática ou alguma orientação feita, a mestranda encontrava-se disponível para o diálogo e esclarecimento.

Conforme pontuado por Freire (2011), no campo da educação, é necessário que a figura docente consiga se entregar, com afetuosidade, ao pensamento crítico, às curiosidades, indagações e inquietações, bem como à realidade vivenciada, e, se encontre

[...]em permanente disponibilidade a tocar e a ser tocado, a perguntar e a responder, a concordar e a discordar. Disponibilidade à vida e a seus contratempos. Estar disponível é estar sensível aos chamamentos que nos chegam, aos sinais mais diversos que nos apelam, ao canto do pássaro, à chuva que cai ou que se anuncia na nuvem escura, ao riso manso da inocência, à cara carrancuda da desaprovação, aos braços que se abrem para acolher ou ao corpo que se fecha na recusa. (FREIRE, 2011, p.89 e 90)

Assim, a mestranda criou a Sala de Aula "Psicoterapia Breve - Semestre Letivo 2021.1" na Plataforma Google Classroom, canal de acesso aos alunos, conforme exemplificado na Figura 2.

Figura 2: Plataforma Google Classroom

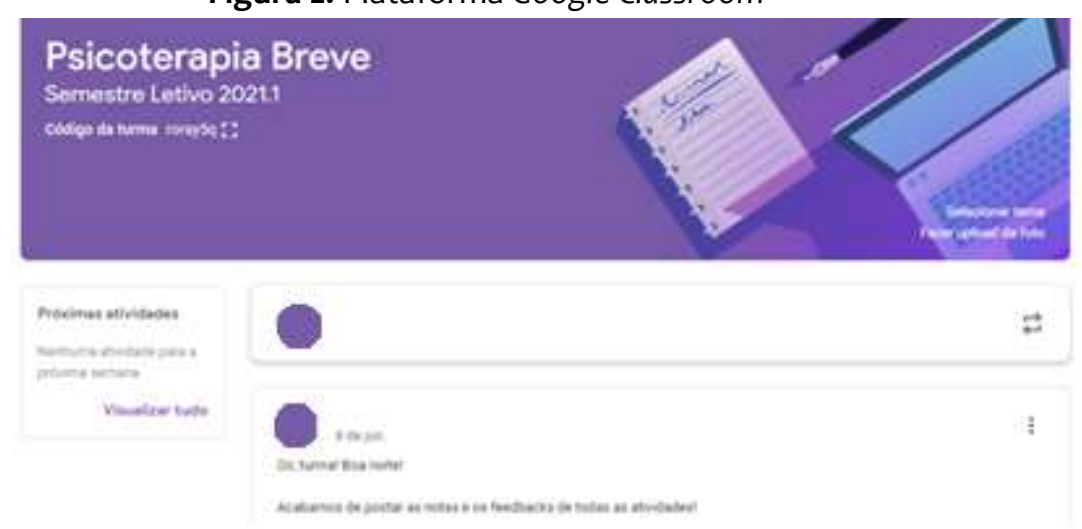

Fonte: Imagem coletada pelas autoras.

\footnotetext{
4 De acordo com o site "Google", na aba de "Ensino e Aprendizagem", o Google Classroom, plataforma de ensino e aprendizagem, constitui uma ferramenta de manejo fácil e seguro, capaz de auxiliar os educadores "a gerenciar, medir e enriquecer a experiência de aprendizagem". Disponível em: https://edu.google.com/intl/ALL_br/products/classroom/.
} 


\section{-Revista de Iniciação à Docência, v.6, n.2, 2021- \\ Publicação: dezembro, 2021 - ISSN 2525-4332}

Ficou estabelecido que as aulas síncronas seriam ministradas pela plataforma Google Meet $^{5}$ e que, na semana que antecedesse cada aula, seria enviado um roteiro prévio que continha: a distribuição do horário (um momento como parte assíncrona para leitura dos textos e um outro momento como parte síncrona para realização da aula), a exposição da temática, as sugestões de leitura (com referências e envio do material em PDF) e o link de acesso ao Google Meet.

A Plataforma utilizada como meio de diálogo com os alunos permitiu, além das postagens de orientações e roteiros prévios, a criação de documentos compartilhados para divisão de grupos para seminários, o envio dos arquivos, a postagem das atividades avaliativas, bem como as entregas dessas.

À medida que as aulas ocorreram, a mestranda e a docente responsável pela disciplina realizavam reuniões periódicas pontuais, após horário da aula, para avaliação do que foi realizado e para concretização de pequenos ajustes no cronograma e na disciplina, caso houvesse a necessidade, corroborando com os argumentos de Freire (2011, p. 27) sobre o quão fundamental é a reflexão crítica sobre a prática: "é pensando criticamente a prática de hoje ou de ontem que se pode melhorar a próxima prática". Nesses momentos, por exemplo, foram perceptíveis as necessidades de alinhamento entre o que havia sido planejado na primeira reunião entre a docente e a mestranda e o que aconteceu na prática, levando em consideração o tempo de compreensão da turma e o tempo ampliado da discussão de algumas temáticas. A partir disso, então, foram realizados ajustes, no cronograma, para que os conteúdos fossem trabalhados de um modo mais aprofundado e não houvesse uma abordagem rápida e superficial dos temas apenas para cumprimento do que havia sido programado inicialmente, afinal, como asseverado por Freire (2011), o processo de aprendizado é composto por um ciclo de construção, reconstrução e constatação do que precisa mudar.

No que tange à possibilidade de reajustes, alteração e modificação o conteúdo programático dada pela docente condutora da disciplina, afirmamos a percepção de que ela deu abertura para as relações de criação e recriação do conteúdo planejado, de um modo a acrescentar transformações a partir do que era posto pelos alunos e pela estagiária, assim eram valorizadas e credibilizadas todas as opiniões e conhecimentos expressados através da linguagem, do diálogo e da comunicação, uma vez que havia posse de que os problemas surgem ao longo do processo e apresentam, assim, causalidade.

A partir da apreensão da causalidade do que era trazido pelos alunos, havia um processo de mão dupla que podemos nomear de conscientização. Esse processo foi vivenciado e experimentado tanto por parte da docente e da estagiária docente, quando se conscientizavam das demandas e necessidades dos alunos, quanto por parte dos

\footnotetext{
${ }^{5}$ Google Meet é um serviço de comunicação por videoconferência que contribui para formar, conectar e incentivar as comunidades escolares, desenvolvido pelo Google.
} 


\section{-Revista de Iniciação à Docência, v.6, n.2, 2021- \\ Publicação: dezembro, 2021 - ISSN 2525-4332}

próprios alunos, quando se conscientizavam, problematizavam e propunham o diálogo conforme as suas percepções. Desse modo, correlacionamos esse processo à consciência crítica que, como postulada por Freire (1967) "é a representação das coisas e dos fatos como se dão na existência empírica. Nas suas correlações causais e circunstanciais".

Dessa compreensão crítica, apreende-se também ações críticas que ocorreram de forma democrática, uma vez que, ao analisarmos a condução de toda a disciplina enxergamos convergências com Freire, percebendo que, em muitos momentos, foram propostas conscientizações, reflexões e problematizações através de um método ativo, participante, dialógico e criticizador.

\section{Encontro docente-discente}

A vivência da docência foi se concretizando ao longo de todo o processo e podemos arriscar dizer que o coroamento do estágio ocorreu quando a mestranda ministrou uma aula teórica, através da Plataforma Google Meet, com o tema: Psicoterapia Breve (PB) no contexto da Psicologia da Saúde e da Psicologia Hospitalar. Foi utilizada uma gama de referências para a construção das aulas, mas, para os alunos, foram sugeridas duas referências obrigatórias e duas referências complementares. A aula ministrada teve o objetivo de abordar a temática, possibilitando com que os discentes matriculados pudessem conhecer a diferença entre as terminologias "Psicologia da Saúde e Psicologia Hospitalar", apreender como é possível aplicar a PB no contexto Hospitalar; refletir sobre as singularidades do ambiente hospitalar; entender quais as indicações para a PB no hospital; compreender conceitos e técnicas relevantes da Terapia CognitivoComportamental na PB; e analisar criticamente a atuação do Psicólogo Hospitalar.

A metodologia utilizada foi a de aula expositiva dialogada, na qual foi feita apresentação com slides e, também, a utilização de imagens com exemplificação de como é realizada uma entrevista na Psicologia Hospitalar. No momento da aula, não houve avaliação, porém foi feita uma verificação de compreensão e aprendizagem dos alunos, por meio do relato dos mesmos e da discussão posterior à parte expositiva, considerando, o que assevera Freire (2011, p. 33): "quando entro em uma sala de aula devo estar sendo um ser aberto a indagações, à curiosidade, às perguntas dos alunos, a suas inibições; um ser crítico e inquiridor, inquieto em face da tarefa que tenho - $a$ de ensinar e não a de transferir conhecimento ${ }^{6 "}$. Nesse propósito, após a exposição, a mestranda obteve um feedback positivo dos discentes matriculados, no qual afirmavam terem gostado das leituras sugeridas e compreendido os assuntos explanados. Os alunos apresentaram, ainda, algumas dúvidas e curiosidades sobre a temática e foram esclarecidos. Nesse momento, inclusive a mestranda utilizou de relatos que envolviam a prática para que as dúvidas fossem sanadas de modo mais claro, considerando, assim, a vivência deles. Ao final, avaliaram que houve clareza e didática adequada, elogiando a performance da mestranda.

\footnotetext{
${ }^{6}$ Destaque do autor.
} 


\section{-Revista de Iniciação à Docência, v.6, n.2, 2021- \\ Publicação: dezembro, 2021 - ISSN 2525-4332}

As dúvidas, por sua vez, como corrobora Freire (2011), já são conhecimento. E, nessa ótica, podemos afirmar que a curiosidade por algo surge a partir do sentimento de estar inacabado enquanto ser humano, isto é, o reconhecer das suas limitações e o estar ciente de que precisa de mais conhecimento para suprir o que já não é mais suficiente. É exatamente a consciência do inacabamento que nos faz seres éticos e responsáveis no mundo. Portanto, compreendemos que o processo de busca e investigação se caracteriza a partir da leitura de mundo do discente e que a curiosidade é inerente ao fato de que os alunos são constituídos enquanto sujeitos históricos, sociais e culturais. Isto é,

no fundo, o educador que respeita a leitura de mundo do educando reconhece a historicidade do saber, o caráter histórico da curiosidade, por isso mesmo, recusando a arrogância cientificista, assume a humildade crítica, própria da posição verdadeiramente científica. (FREIRE, 2011, p.82)

\section{Atendimentos individuais e coletivos}

A mestranda ficou responsável pela postagem dos roteiros de aula, textos de referência para leitura e postagem das atividades avaliativas na Plataforma Google Classroom. Desse modo, na medida em que os alunos tinham dúvidas e precisavam de esclarecimentos referentes ao componente curricular ou algum dos pontos mencionados, a mestranda respondia aos comentários de dúvidas em chat particular no Google Classroom, via e-mail ou via Whatsapp, em uma prática dialógica, respeitando o princípio de que todo o processo do estágio envolve construção. Assim, ancoradas nas palavras de Freire (2011, p. 41) quando diz que "os sujeitos dialógicos aprendem e crescem na diferença, sobretudo, no respeito a ela, é a forma de estar sendo coerentemente exigida por seres que, inacabados, assumindo-se como tais se tornem radicalmente éticos", os atendimentos prezavam pelo respeito à autonomia dos discentes.

Aqui, reafirmamos que só há a comunicação, como afirmado por Freire (1967), quando "instala-se, então, uma relação de simpatia entre ambos". Com efeito, ao nos possibilitarmos para o diálogo, fomos capazes de estimular os sentidos e significados que foram apreendidos pelos alunos, bem como compreender como foi simbolizada a relação de mediação estabelecida dentro do processo de ensino-aprendizagem, afinal não era de desejo realizar uma prática bancária de transferência de conhecimento, mas, sim, uma prática reflexiva, crítica e problematizadora, que criasse possibilidades.

Além dos esclarecimentos de dúvidas individuais, houve momentos na disciplina que foram direcionados para orientação de grupos (com fins na realização de trabalhos escritos ou orais). Dessa forma, houve também atendimento e orientação coletiva aos discentes matriculados. Durante o período assíncrono, a mestranda também se encontrava à disposição para eventuais necessidades, tendo em vista que, como pontuado por Freire (2011), o ambiente educativo compreende também um espaço de suporte, que abrange a linguagem, a cultura e a comunicação como pilares fundamentais 
para permitirem que o processo de ensino-aprendizagem seja uma prática formadora e ética.

O espaço de suporte, ao tirar as dúvidas dos discentes e manter-se disponível ao diálogo, permitiu a nós, na condição de docentes, o crescimento e maior domínio do conhecimento, uma vez que, em concordância com Freire (1967), entendemos que o professor deve manter uma postura de abertura e disponibilidade para com o outro, afinal, a relação ocorre entre sujeitos embutidos de histórias, relações e imersão em diversos contextos e não apenas pela relação educacional entre professor- aluno e é, nesse viés que, através dos conhecimentos científicos e cotidianos, concordamos que "quem ensina aprende ao ensinar e quem aprende ensina ao aprender" (FREIRE, 2011).

Aqui é pertinente dizer que compreendemos que a educação se forma à medida que sentimos necessidade de obtenção de mais conhecimentos e, para isso, as dúvidas são o caminho inicial. Portanto, aliada à curiosidade dos discentes, é necessário que o docente, por meio de uma prática formadora e ética, atue com respeito às divergências de pensamentos, assegurando a autonomia e a identidade discente. Por vezes, no componente curricular, emergiram discussões sobre qual seria considerada a abordagem teórica da Psicologia “mais adequada” para realização da Psicologia Breve.

Nesse aspecto, como docentes, frisamos a necessidade de que houvesse o respeito à diversidade de abordagens escolhidas entre os discentes, como fundamento que legitime a autonomia e liberdade de escolhas, incluindo o fato de que a diversificação proporcionará uma experiência formativa mais enriquecedora para todos os envolvidos no processo. Inclusive partindo do pressuposto de que não há uma única verdade/conhecimento, mas que é possível proporcionar o diálogo entre os saberes, de modo a pensar todo o arcabouço histórico e social que contempla as discussões.

\section{Participação na avaliação}

Conforme combinado entre a docente responsável e a mestranda, durante o planejamento do componente curricular, a mestranda faria participação nos processos de avaliação da aprendizagem. Assim, entre as quatro atividades avaliativas, compostas por: 1. Elaboração de um glossário com os principais termos utilizados na PB; 2. Apresentação de seminário sobre PB e contextos de atuação; 3. Elaboração escrita do plano de intervenção em PB; e 4. Apresentação oral do plano de intervenção em PB, a mestranda participou das avaliações 1,3 e 4, excetuando o Seminário sobre contextos de atuação, que foi avaliado somente pela docente da disciplina.

Referente à atividade 1. Glossário (Figura 3), a avaliação foi feita com base nos alunos que realizaram a atividade no prazo estipulado e que conseguiram contemplar o que havia sido orientado: a quantidade de termos solicitada (no mínimo 15), os termos estarem com conceitos pertinentes ao assunto que foi estudado e a organização do material produzido. As avaliações foram realizadas através do Google Classroom, de modo que foram realizados comentários particulares com feedback. 
Figura 3: Orientação para atividade avaliativa “Glossário”, disponível na Plataforma Google Classroom

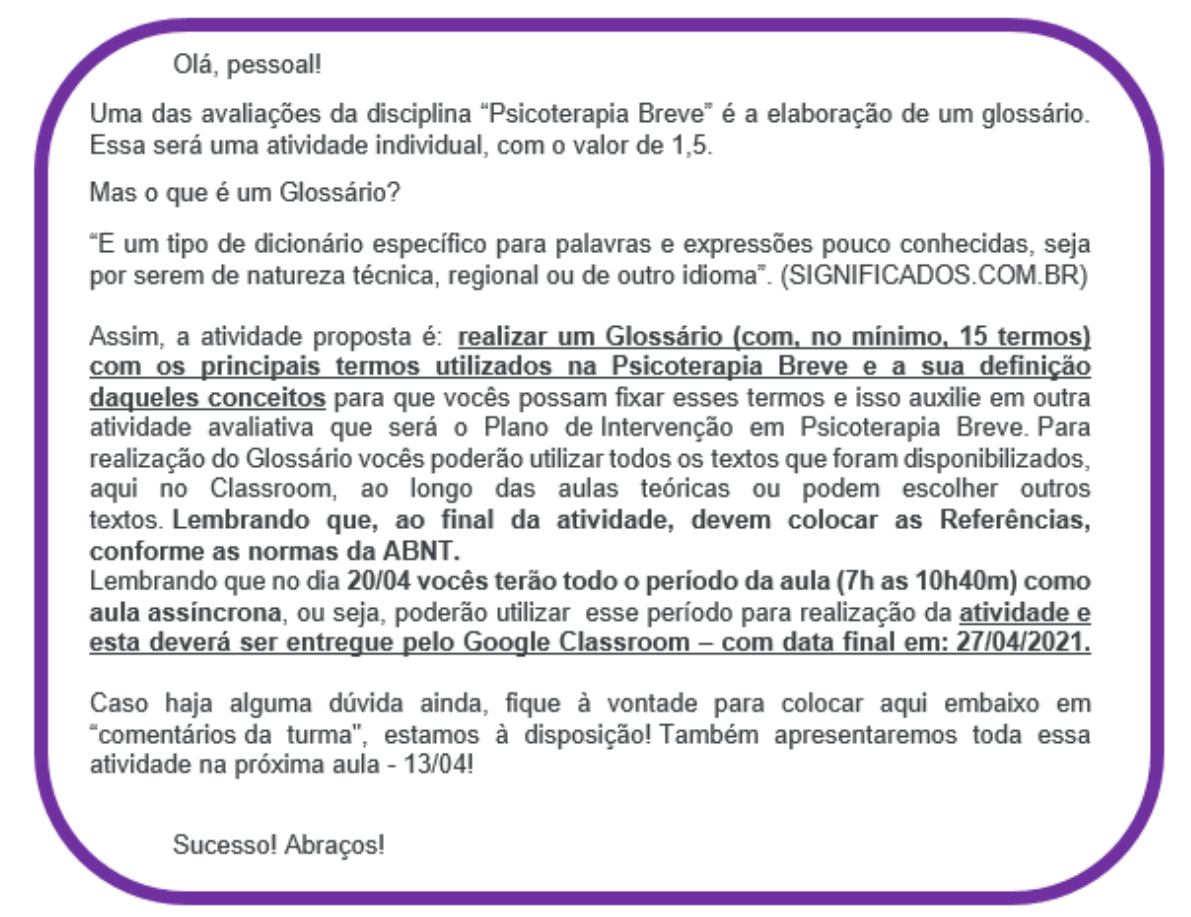

Fonte: Imagem coletada pelas autoras.

Quanto à avaliação da Elaboração escrita do plano de intervenção em PB, a mestranda ficou responsável pela escolha/elaboração dos casos fictícios a serem utilizados pelos grupos. Ao elencarmos essa atividade como avaliativa, não tivemos o desejo de mecanizar o conhecimento, mas, sim, o desejo de que os discentes pudessem participar ou construir esse conhecimento prático referente aos objetos de estudo, os casos clínicos. Assim, os casos foram escolhidos e repassados aos grupos, conforme foram divididos, para, então, a realização do Plano. Após a entrega, os planos escritos foram avaliados na pertinência e adequação das etapas do plano às técnicas utilizadas e à abordagem escolhida.

Para essa avaliação, então, foi disponibilizado um modelo a ser seguido com capa/identificação e descrição do que deveria compor o Planejamento Terapêutico (Figura 4), a exemplo de: 1. descrição do caso (já enviado), 2. Breve análise teórica (de acordo com a abordagem teórica escolhida, fundamentada em referências científicas), 3. Foco terapêutico (com motivo da consulta e conflito nuclear; aspectos caracterológicos individuais do paciente: potencialidades, dificuldades e estratégias compensatórias; aspectos históricos e genéticos; situação grupal; determinantes do contexto social mais amplo), 4. metas terapêuticas, 5. propostas de intervenção (que deveriam ser, no mínimo 8 e, no máximo 10 sessões: cada sessão deveria ser composta pelo objetivo da sessão, quais técnicas e intervenções seriam utilizadas e a justificativa para escolha da técnica), 6 . prognóstico do caso e resultados esperados e referências, conforme a ABNT. 
Quanto à avaliação da parte oral do plano de intervenção em PB, a mestranda ficou responsável por criar um barema com critérios para avaliação e, desse modo, conforme havia as apresentações, foram considerados critérios como: domínio do conteúdo, qualidade científica das informações apresentadas, utilização de material de apoio (slides) e manejo do tempo.

Figura 4: Modelo resumido do "Planejamento Terapêutico em PB"

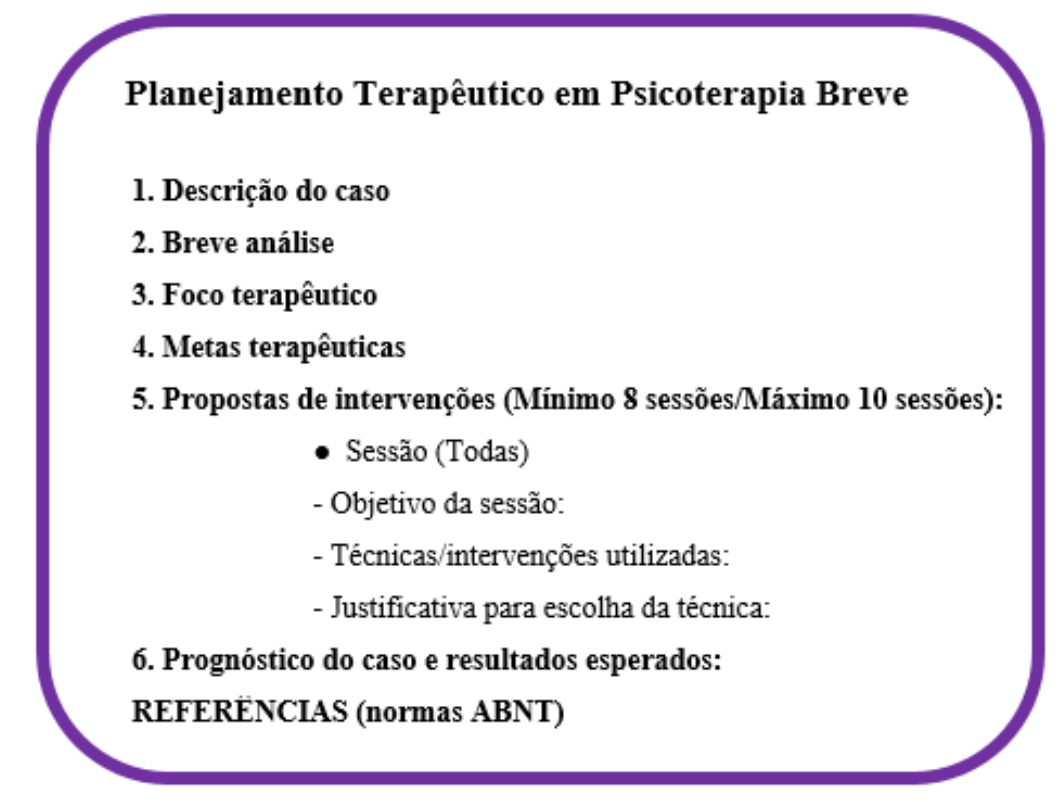

Fonte: Imagem coletada pelas autoras.

Portanto, a ordem das avaliações foi constituída a partir do desejo de que: os alunos conseguissem ter domínio no campo teórico, que seria possibilitado pela atividade do glossário (atividade 1); ao analisar os contextos de atuação em que ocorrem a PB (atividade 2), fossem capaz de correlacionar teoria com campos de atuação; e ao fazer o plano de intervenção (atividades 3 e 4), mediante distribuição dos casos, tivessem condições de articulação de conhecimento teórico e prático para, enfim, elaborar um raciocínio clínico para construir um plano de intervenção, apreendendo todos os aspectos que envolvem o caso. Sendo, desta maneira, evidenciada a construção de um aprendizado, por etapas, mas que ocorresse de maneira mais prática e autônoma, afinal para conseguirem concretizar o conhecimento foram incentivados na busca por investigar às suas próprias inquietações.

Nesse sentido, ainda, é importante ressaltarmos que as formas de avaliação foram elencadas pelas docentes anteriormente ao componente devido à necessidade de uma metodologia sistematizada coerente com o plano de curso, o que não significa dizer que foi imposta uma única forma de realização das atividades, pois, embora houvesse um "molde" a ser seguido, como critério para avaliação, foi prezada a autonomia dos discentes, que ficaram livres para se organizarem da forma como julgassem melhor, desde a escolha de materiais acadêmicos para embasar os trabalhos, perpassando pelas 


\section{-Revista de Iniciação à Docência, v.6, n.2, 2021- \\ Publicação: dezembro, 2021 - ISSN 2525-4332}

abordagens teóricas e materializando no formato da apresentação. Assim, a autonomia possibilitada gerava, também, a necessidade de responsabilidade.

No tocante ao estímulo da autonomia, ponderamos ainda sobe a democratização do processo de aprendizagem, pois, ainda que as docentes tenham ficado responsáveis pela mediação e facilitação do conhecimento, para propiciar um melhor entendimento quanto aos conteúdos desconhecidos, as docentes colocaram-se como profissionais em constante transformação, de modo inacabado, fazendo com que o diálogo e a participação conjunta e coletiva fossem aspectos incisivos para a práxis docente. Nesse sentido, a gama de métodos de avaliação, como a participação e a elaboração de trabalhos e seminários, supera os procedimentos técnicos e democratiza o conhecimento, ao possibilitar aos alunos uma imersão, levando elementos teóricos para uma prática, fazendo os alunos se movimentarem para transformação e extinguindo a possibilidade de passividade frente ao processo ensino-aprendizagem (FREIRE, 1997).

Mediante à ponderação entre as avaliações realizadas pela mestranda e pela docente, foi elaborado e enviado aos grupos, via e-mail, um documento no formato Word que continha um parecer e um feedback sobre as avaliações (escrita e oral) do plano de intervenção, bem como sugestões de ajustes no texto relativas às normas da ABNT.

Ao final do semestre, os pareceres e feedbacks de todas as avaliações foram enviados aos alunos (via e-mail e Google Classroom) e as docentes se mantiveram à disposição para o esclarecimento de dúvidas que, porventura, viessem a surgir.

\section{Considerações finais}

Em avaliação ao estágio docente orientado realizado durante a pandemia, na modalidade remota, consideramos que cumprimos as atividades propostas de maneira satisfatória, pois estivemos presentes e disponíveis para o envolvimento com as atividades desde a elaboração do cronograma, na sugestão de atividades avaliativas, perpassando pela presença nas aulas ministradas, nas reuniões pontuais que foram realizadas até o momento em que culminaram as avaliações e no feedback para os alunos.

A experiência com o estágio docente permitiu vivenciar as nuances que envolvem o processo de ensino-aprendizagem, neste momento, em uma outra condição, com o foco no processo de formação docente. Então, podemos afirmar que a vivência foi bastante significativa no que diz respeito às experiências de planejar; escolher criteriosamente as referências; preparar a aula pensando em recursos que poderiam ser utilizados para facilitar o manejo e a didática; estabelecer critérios de avaliação; e, também, as emoções que envolvem o "me disponibilizar para o relacionar com o aluno".

Afinal, a forma como nos permitimos relacionar foi condizente com a forma como nós compreendemos que o ensino-aprendizagem deva acontecer, mediada pelo processo dialógico e de troca de saberes. 
A práxis do Estágio Docente foi uma experiência ímpar, enriquecedora e muito importante para a nossa formação pessoal, profissional e acadêmica, uma prática reflexiva que estimulou a ampliação da nossa concepção de docência. Acreditamos que, diante da nossa postura proativa, engajada e motivada, fomos exitosas no que entendemos por ser o objetivo do estágio docente: a experimentação do exercício de lecionar no ensino superior. Percebemos ainda que:

ensinar e aprender têm que ver com o esforço metodicamente crítico do professor de desvelar a compreensão de algo e com o empenho igualmente crítico do aluno de ir entrando como sujeito em aprendizagem, no processo de desvelamento que o professor ou professora deve deflagrar. Isso não tem nada que ver com a transferência de conteúdo e fala da dificuldade, mas, ao mesmo tempo, da boniteza da docência e da discência. (FREIRE, 2011, p.79)

Quando nos referimos a práxis freireana, objetivamos conectar e articular teoria e prática, integrando o compartilhamento de saberes por meio das experiências construídas de maneira coletiva, tanto pela docente que conduziu a disciplina, como pela estagiária docente e pelos alunos que compuseram a turma de PB.

Entendemos que as construções coletivas ocorrem por meio da comunicação que possibilita a transformação da realidade posta à medida que nos entendemos como sujeitos sociais, históricos e culturais e vivenciamos as situações voltadas, aqui, para o processo ensino-aprendizagem. Assim, a relação dialógica que compõe a práxis no entrecruzar teoria e prática apresenta, para nós, sentido e significado ao efetivar o ato de ensinar e aprender, nesse contexto e processo de aprendizagem do estágio docente.

Por fim, consideramos também que a condução desse estágio docente ocorreu de forma leve e fluída pela maneira em que ocorreu a condução da disciplina, na busca inquieta e permanente por fazer com que os alunos se envolvessem com a disciplina, uma prática transformadora e libertadora, que não esteve fixa, mas, sim, em movimento, a partir do momento em que nos reconhecemos como seres inacabados e temos ciência dos desejos por dinamicidade e mudanças no processo educacional. (FREIRE, 1997)

Avaliamos, portanto, que o objetivo do relato de experiência foi alcançado ao lançar um olhar freireano para o estágio docente, como vislumbrado, afinal ainda que a metodologia da docente responsável pela disciplina não tenha sido explicitamente de acordo com esse referencial, podemos avaliar que foram utilizados elementos e pressupostos para uma educação libertadora, dialógica e problematizadora, o que significa ter realizado um trabalho com o estímulo à autonomia dos discentes matriculados na disciplina. Nesse contexto, esperamos, para além do desejo de explicitar às condições vinculadas ao ensino remoto no contexto pandêmico, que este relato possa contribuir com a prática de psicólogos em formação docente, uma vez que nos deparamos com essa lacuna existente em nossos cursos. 


\section{Referências}

BRASIL, MINISTÉRIO DA EDUCAÇÃO. Resolução CNE/CES nº 5, de 15 de março de 2011. Institui as Diretrizes Curriculares Nacionais para os cursos de graduação em Psicologia, estabelecendo normas para o projeto pedagógico complementar para a Formação de Professores de Psicologia. Brasília, DF, 2011. Disponível em:

http://www.abepsi.org.br/wp-content/uploads/2011/07/DCN-201121.pdf. Acesso em: 05 jul. 2021.

FREIRE, P. Pedagogia da autonomia: saberes necessários à prática educativa. 5. ed. São Paulo: Paz e Terra, 2011.

FREIRE, P. Educação como prática da liberdade. Rio de Janeiro: Paz e Terra, 1967. Disponível em :

http://www.gestaoescolar.diaadia.pr.gov.br/arquivos/File/otp/livros/educacao_pratica_lib erdade.pdf. Acesso em 22 nov. 2021.

FREIRE, P. Educação "bancária" e educação libertadora. In: PATTO, M. H. S. (Org.). Introdução à psicologia escolar. 3. ed. São Paulo: Casa do Psicólogo, 1997, p.61-81.

GOOGLE FOR EDUCATION. Disponível em:

https://edu.google.com/intl/ALL_br/products/classroom/. Acesso em julho 2021.

INÁCIO, A. M.; RONQUI, D. D.; MANDELLI, J. P.; SCHMIDT, K. G. A. V. Estágio docente em modalidade remota: breve relato de experiência em tempos pandêmicos. In: Seminário Nacional de Pesquisa em Educação - Pesquisa, docência e conhecimento: desafios para a pós-graduação em tempos de conservadorismo reacionário, 3, 2020, Pelotas.

Anais...Pelotas: III SENPE, 2020, p.1-8. Disponível em:

https://portaleventos.uffs.edu.br/index.php/SENPE/article/view/14792. Acesso em: 06 jul. 2021.

SILVA, J.A.O.; RANGEL, D.A.; SOUZA, I.A. Docência superior e ensino remoto: relatos de experiências numa instituição de ensino superior privada. Rev. Docência Ens. Sup., Belo Horizonte, v. 10, p.1-19, 2020. Disponível em:

https://periodicos.ufmg.br/index.php/rdes/article/view/24717/20288. Acesso em: 29 jun. 2021.

UFBA. Instrução Normativa № 01 /2019, de 10 de junho de 2020. Regulamenta as normas para o Estágio Docente Orientado, do Programa de Pós-Graduação em Psicologia da Saúde, do Instituto Multidisciplinar em Saúde da Universidade Federal da Bahia, 2020. Disponível em:

https://psicologiasaudeims.ufba.br/sites/psicologiasaudeims.ufba.br/files/intrucao_norma tiva_no_012019_estagio_docencia_ppgps.pdf. Acesso em: 05 jul. 2021.

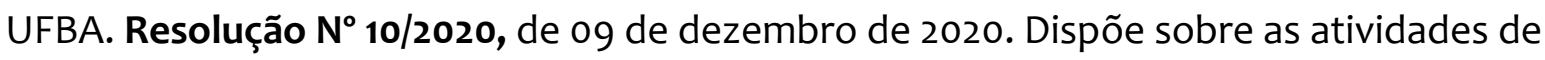
ensino no semestre 2021.1 para os cursos de graduação e de pós-graduação stricto sensu, da UFBA, 2020. Disponível em:

https://ufba.br/sites/portal.ufba.br/files/resolucoes/resolucao_no_10.2020__cae.pdf. Acesso em: 28 nov. 2021.

ZANOTTO, L.; OLIVEIRA, R.F.B.; SOMMERHALDER, A. A docência diante do ensino remoto: limites e desafios ao ensino na formação de professores. In: Congreso Iberoamericano de Docentes - Docentes frente a la pandemia, 2, 2021. Anais... Revista 
-Revista de Iniciação à Docência, v.6, n.2, 2021-

Publicação: dezembro, 2021 - ISSN 2525-4332

Formación IB, p. 1-6. Disponível em: http://formacionib.org/programa/012.pdf. Acesso em: 05 jul. 2021.

$* * *$

Recebido: 13.08 .2021

Aprovado: 06.12.2021 